Regards sur l'économie allemande

Bulletin économique du CIRAC

$68 \mid 2004$

Varia

\title{
Patrons : des salaires justifiés aux yeux des
}

Allemands

\section{Isabelle Bourgeois}

\section{(2) OpenEdition}

1 Journals

Édition électronique

URL : https://journals.openedition.org/rea/3636

DOI : 10.4000/rea.3636

ISBN : 978-2-8218-0832-4

ISSN : 1965-0787

\section{Éditeur}

CIRAC

Édition imprimée

Date de publication : 1 octobre 2004

Pagination : 35-36

ISSN : 1156-8992

Référence électronique

Isabelle Bourgeois, "Patrons : des salaires justifiés aux yeux des Allemands », Regards sur l'économie allemande [En ligne], 68 | octobre 2004, mis en ligne le 29 avril 2009, consulté le 21 septembre 2021. URL : http://journals.openedition.org/rea/3636 ; DOI : https://doi.org/10.4000/rea.3636

Ce document a été généré automatiquement le 21 septembre 2021.

(c) CIRAC 


\title{
Patrons : des salaires justifiés aux yeux des Allemands
}

\author{
Isabelle Bourgeois
}

\section{$67 \%$ des Allemands : les hauts salaires ne sont pas immoraux}

1 Dans le contexte des manifestations contre la réforme du système des indemnités chômage («Hartz IV ), l'un des arguments avancés par les opposants à ce «démantèlement des acquis sociaux" est l'injustice foncière que constituerait le niveau des salaires des patrons, certains allant jusqu'à en réclamer un plafonnement. On met en regard les $345 €$ mensuels du nouveau «RMI » allemand et la douzaine de millions d'euros que gagneraient un Rolf Breuer (ex-président du directoire de Deutsche Bank) ou un footballeur professionnel. Par-delà la polémique, que pensent réellement les Allemands des hauts salaires? Pour en avoir le cœur net, le magazine Chrismon a commandité cet été auprès de l'institut TNS Emnid un sondage centré sur la question. "Les salaires versés par millions aux sportifs ou aux patrons sont-ils immoraux ? ». Non, répondent $67 \%$ des sondés.

\begin{tabular}{|l|l|}
\hline \multicolumn{2}{|l|}{ Les salaires versés par millions aux sportifs ou aux patrons sont-ils immoraux ?... } \\
\hline \hline ... ils sont OK tant que les millionnaires s'engagent dans le sens de l'intérêt général & $30 \%$ \\
\hline \hline ... ils sont OK tant que les millionnaires valent leur salaire & $27 \%$ \\
\hline \hline ... les revenus dépassant un certain seuil sont de toute façon immoraux & $30 \%$ \\
\hline \hline ... il n'y a pas de seuil moral de revenus, à chacun de négocier le maximum & $10 \%$ \\
\hline
\end{tabular}


\begin{tabular}{|l|l|}
\hline ... n.s.p. & $3 \%$ \\
\hline
\end{tabular}

Source : chrismon 08/2004. Sondage commandité à TNS Emnid, réalisé les 23/24-06-2004 auprès

d'un échantillon représentatif de 1006 personnes de 14 ans et plus (www.chrismon.de).

\section{L'attachement profond aux valeurs fondatrices du « modèle rhénan »}

2 Les opinions varient selon les sexes. Ainsi, les femmes sont plus nombreuses à privilégier l'intérêt général que les hommes ( $35 \%$ contre $25 \%$ ); elles sont plus nombreuses aussi à considérer les hauts salaires comme immoraux ( $33 \%$; hommes : $27 \%)$. A l'inverse, les hommes accordent plus d'importance à la notion de mérite (36\%, contre $19 \%$ de femmes seulement). La désapprobation croît avec l'âge : les 60 ans et plus sont $39 \%$ à trouver immoraux les hauts salaires, alors que les 14-29 ans ne sont que $17 \%$. Curieusement, les deux extrêmes se rejoignent sur la valeur accordée à l'intérêt général : ils sont $33 \%$ dans les deux cas, le taux de réponses étant inférieur dans les autres tranches d'âge, sauf chez les 50-59 ans (38\%). Cette tranche d'âge-là, née juste après la guerre, est encore porteuse des valeurs constitutives de l'économie sociale de marché et contemporaines du "miracle économique ». A l'opposé, la notion de mérite caractérise les plus jeunes ( $37 \%$ des 14-29 ans), reflet de la mutation des valeurs et de l'individualisation des modes de vie et de comportement. Mais dans l'ensemble, l'attachement à l'engagement de l'individu dans la société, à la part de responsabilité qu'il porte dans la genèse de la prospérité collective, demeure profond, comme le révèle l'approbation $(30 \%)$ des hauts salaires dès lors qu'ils servent l'intérêt général.

\section{Différences culturelles entre l'est et l'ouest de la RFA}

Les différences est-ouest sont patentes : 42 \% des Allemands de l'est considèrent comme «de toute façon immoraux » les hauts salaires ( $26 \%$ à l'ouest seulement). Les taux de réponses aux deux justifications proposées varient en conséquence : l'intérêt général (26\% à l'est, mais tout de même $31 \%$ à l'ouest) l'emportant sur le mérite (22 \% à l'est contre $28 \%$ à l'ouest). Ces différences régionales sont d'ordre culturel. Schématiquement, elles reflètent, à l'est, l'héritage de 40 ans de socialisation marxiste avec l'opposition tranchée entre travail et capital, la valeur accordée à l'égalitarisme et, plus important encore, une notion de l'intérêt général qui diffère profondément de ce qu'elle est à l'ouest en ce sens qu'elle implique la prépondérance de l'Etat. A l'ouest, elles reflètent l'identification avec la doctrine de l'économie sociale de marché et ses valeurs : la conciliation du travail et du capital, une définition de l'intérêt général basée sur la responsabilité de l'individu (expression du principe de subsidiarité) et la prédominance du principe d'équité (opposé à égalité). L'unité n'a pas effacé ces différences qui contribuent d'ailleurs à expliquer pourquoi ce sont surtout les Allemands de l'Est qui manifestaient cet été contre la loi Hartz IV et pourquoi, lors des élections régionales dans le Brandebourg le 19-09-04, le parti PDS, héritier du Parti-Etat de l'ex-RDA, a rallié autant de suffrages. 


\section{Une éthique protestante toujours vivace}

4 Ce n'est pas un hasard si ce sondage a été commandité par le magazine chrismon. Ce mensuel de société défend en effet les valeurs protestantes - dont le principe d'équité sous-jacent au libéralisme organisé. Il est distribué sous forme de supplément par cinq quotidiens, dont le Frankfurter Rundschau récemment racheté par le SPD, et par l'hebdomadaire Die Zeit, dont le directeur de publication n'est autre que l'ancien chancelier Helmut Schmidt (SPD). Mais le sondage n'est pas le prolongement de la communication gouvernementale sur les réformes. Car l'équité est une des grandes questions qui préoccupent depuis toujours la société allemande (voir REA 59/02) - un peu plus aujourd'hui, bien sûr, dans le contexte des réformes qui tentent de rompre avec la dérive égalitariste qu'a connue la valeur fondatrice de l'organisation économique et sociale allemande: l'équité des chances, approche «rhénane » de la « justice sociale ». (IB)

INDEX

Mots-clés : patronat, salaire, revenu, opinion publique 